University of Nebraska - Lincoln

DigitalCommons@University of Nebraska - Lincoln

2003

\title{
A Biologic Model for Assessment of Osseous Strain Patterns and Plating Systems in the Human Maxilla
}

\author{
L. Russell Alberts \\ Alberts Biomechanics, LLC, Omaha, NE. \\ Kenneth O. Phillips \\ Kaiser-Permanente, Sacramento Medical Center, Sacramento, CA \\ Harold K. Tu \\ Surgery, College of Medicine, University of Nebraska Medical Center, Omaha, NE \\ Warren W. Stinson \\ Surgery, College of Medicine, University of Nebraska Medical Center, Omaha, NE \\ Andrew Friedman \\ US Army, Washington, DC
}

Follow this and additional works at: https://digitalcommons.unl.edu/usarmyresearch

Part of the Operations Research, Systems Engineering and Industrial Engineering Commons

Alberts, L. Russell; Phillips, Kenneth O.; Tu, Harold K.; Stinson, Warren W.; and Friedman, Andrew, "A Biologic Model for Assessment of Osseous Strain Patterns and Plating Systems in the Human Maxilla" (2003). US Army Research. 3.

https://digitalcommons.unl.edu/usarmyresearch/3

This Article is brought to you for free and open access by the U.S. Department of Defense at DigitalCommons@University of Nebraska - Lincoln. It has been accepted for inclusion in US Army Research by an authorized administrator of DigitalCommons@University of Nebraska - Lincoln. 


\title{
A Biologic Model for Assessment of Osseous Strain Patterns and Plating Systems in the Human Maxilla
}

\author{
L. Russell Alberts, PbD, * Kenneth O. Phillips, DMD, MD, $†$ \\ Harold K. Tu, DMD, MD, $\neq$ Warren W. Stinson, PbD, $\mathbb{\complement}$ \\ and Andrew Friedman, $M D \|$
}

\begin{abstract}
Purpose: This study was conducted to examine a biomechanical model and to help answer fundamental questions that relate to rigid plate fixation in the maxilla. Specifically, we sought to elucidate the principal strain patterns generated in the maxilla secondary to masticatory forces as well as the amount of permanent deformational changes incurred due to these loading forces.
\end{abstract}

Materials and Methods: Cadaveric heads with the mandible removed were defleshed and placed in a 2-part testing rig to hold and position the skull for testing in a standard material testing system. Rosette strain gages were attached at predefined points on the skull, and an Instron machine was used to load the skull through the loading port on the tray. A Le Fort I osteotomy was then performed on the skull, and a Walter Lorenz Ultra-Micro plating system was applied by a surgeon to reconnect the upper jaw. A 2-mm gap was left at the line of the osteotomy, and a transducer was attached to measure closure of the gap. Again the skull was loaded with the Instron (Canton, MA) machine.

Results: The results indicate a linear relationship exists with both maximum (tensile) and minimum (compressive) strain patterns relative to incremental load placement on the intact maxilla. The strain patterns after the Le Fort I osteotomy and plating were different and less linear. The differential variable reluctance transducer data showed a low rate of closure or transient increase in the gap at low loads (0 to 15 kilopond [kp] range) and a steeper slope of closure during high loads ( 15 to $60 \mathrm{kp}$ range). It is also evident that axial loading forces cause permanent deformation and failure of osseous plating systems predominantly through bending.

Conclusions: This model provides a foundation of knowledge regarding biomechanical strains in the maxilla subjected to static compressive loads in the force range of mastication. In addition, it serves as a comparative reference to assess rigidity of various craniofacial plating systems and to validate proposed standardized synthetic models. With the advent of increasingly precise surgery and new plating systems, this model can be used to help guide placement and design of plating systems; thereby allowing for ideal stabilization and optimizing surgical outcome.

(1) 2003 American Association of Oral and Maxillofacial Surgeons

J Oral Maxillofac Surg 61:79-88, 2003

*President, Alberts Biomechanics, LLC, Omaha, NE.

tPlastic Surgery, Kaiser-Permanente, Sacramento Medical Center, Sacramento, CA.

¥Associate Professor, Surgery, College of Medicine, University of Nebraska Medical Center, Omaha, NE.

\Associate Professor, Cell Biology and Anatomy, College of Medicine, University of Nebraska Medical Center, Omaha, NE.

\|US Army, Washington, DC.

This study was supported by Biomet and Walter Lorenz.

Address correspondence and reprint requests to Dr Alberts: Alberts Biomechanics, LLC, 4426 S 187th St, Omaha, NE 68135; e-mail: russ@albertsbiomechanics.com

(c) 2003 American Association of Oral and Maxillofacial Surgeons

0278-2391/03/6101-0014\$35.00/0

doi: $10.1053 /$ joms. 2003.50013
The use of rigid plate fixation devices has become common in maxillofacial surgery in the United States to treat trauma and congenital defects. Although numerous studies illustrate the osseous strain patterns encountered in the mandible, ${ }^{1-3}$ remarkably little has been published regarding the maxilla. Despite this, plating of the maxilla has occurred with good success using various plating systems. However, due to the ever-increasing precision of surgical movements, questions have arisen regarding stability, ideal placement, and number and size of plates necessary for optimal outcome in the maxilla. This study was brought forth to help develop a model that can be used to answer some of those questions. Specifically, we sought to elucidate the principal strain patterns generated in the maxilla secondary to masticatory forces as well as the amount of permanent 
deformational changes incurred due to these compressive loading forces.

A solid understanding of changes in the biomechanics of the maxilla is necessary to adequately evaluate new titanium craniofacial plating systems as well as systems that use resorbable polymers, such as poly(L)lactide (PLLA) and polyglycolic acids (PGA). ${ }^{4}$ Ideally, such resorbable plates should be able to maintain the stability of the maxilla during healing and then be completely resorbed with no inflammatory reaction. Early experiments with these resorbable materials show that there frequently are adverse reactions during the resorption stage..$^{5-7}$ To characterize the biomechanical aspect of resorbable and titanium plating systems, a better understanding of the maxilla biomechanics in both intact and plated situations is necessary.

We will 1) describe a model that can be used to investigate the biomechanics of various craniofacial plates in cadaveric heads and 2) investigate the strain pattern at predetermined sites in the maxillae under static loads similar in magnitude to those that occur during mastication in several embalmed heads. This model, although not necessarily duplicating mastication nor characterizing the strain distribution throughout the entire cranium, is a first-order study of the strain distribution in the intact and plated maxilla.

\section{Materials and Methods}

\section{SPECIMENS}

We report on a series of trials performed on embalmed, defleshed human cadaveric skulls from the Anatomy Department at the University of Nebraska Medical Center (Omaha, NE). Initial work was performed on 2 skulls to assess the testing rig and strain gauge application techniques. This report deals with the preosteotomy results and analysis of 4 skulls (skulls 3 through 6) from subjects ranging in age from 63 to 87 years ( 3 men and 1 woman). Due to accidental damage that occurred to skull 6 (female), postosteotomy results are reported on skulls 3 through 5 .

\section{SKULL PREPARATION}

Embalmed cadaveric skulls were manually debrided of all soft tissue with a scalpel in preparation of reference markings. Until the tests were performed, the skulls were kept moist in refrigerated physiologic saline solution to prevent further change to their viscoelastic properties. $^{8}$ Standardized reference points were established to allow exact positional placement of strain gauges from skull to skull. Similar reference markings were used for the differential variable reluctance transducer (DVRT).

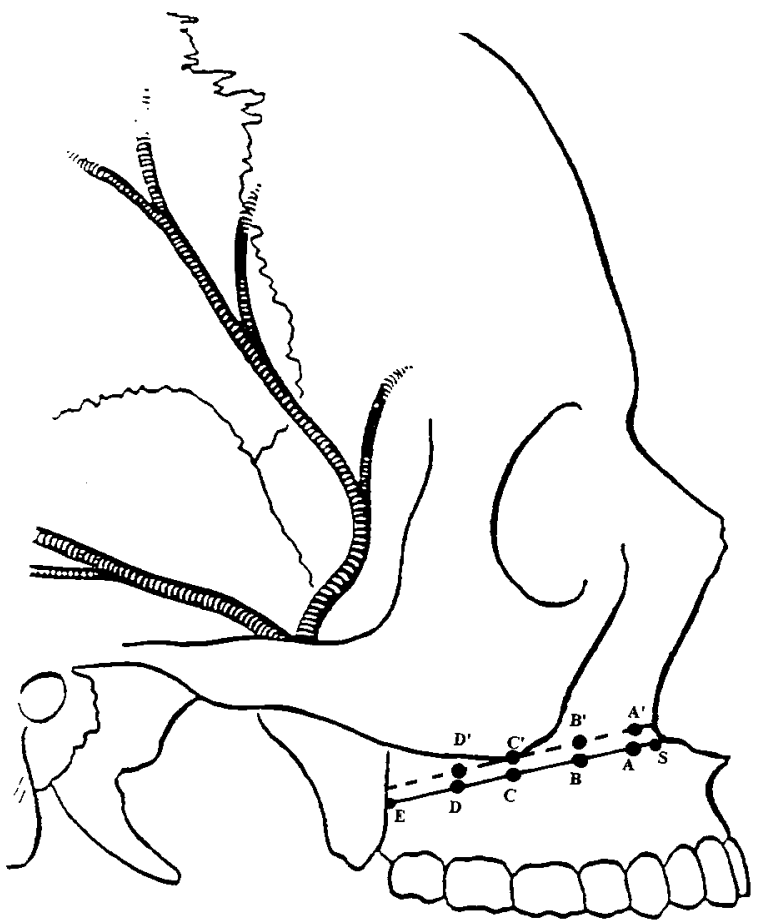

FIGURE 1. Bony landmarks on human skull used to establish Le Fort I osteotomy line and placement of strain gauges. The following steps were used to establish the landmarks: 1) Establish point $S$ at intersection of lines tangent to the vertical and horizontal aspects of piriform rim. 2) Establish point E $1 \mathrm{~cm}$ superior at pterygomaxillary fissure. 3) Draw osteotomy line from point $S$ to point $E$, and along this line establish (3.1) point A $5 \mathrm{~mm}$ distal to point $S$, (3.2) point $C$ at one-half the distance between $A$ and $E,(3.3)$ point $B$ at one-half the distance between $A$ and $C$, and (3.4) point $D$ at one-half the distance between $C$ and E. 4) Establish the strain gage line $5 \mathrm{~mm}$ superior and parallel to the osteotomy line. 5) Place strain gauges at points $A^{\prime}$ (piriform rim region), B', C' (zygomatic buttress region), or D' (posterior zygomatic buttress region).

\section{STRAIN GAUGES AND INSTRUMENTATION}

This study involved the use of stacked rosette strain gauges (No. WA-06-030WY-120; MicroMeasurements Inc, Raleigh, NC) to record osseous stress patterns. The strain gauges are attached via an epoxy resin and sealed with Silastic silicone rubber. ${ }^{9}$ Strain gauges were originally standardized to 4 points $\left(\mathrm{A}^{\prime}, \mathrm{B}^{\prime}, \mathrm{C}^{\prime}\right.$, $\mathrm{D}^{\prime}$; Fig 1) on each maxillary bone, in the region of the posterior zygoma, zygomatic buttress, mid-maxilla, and piriform rim. However, it was determined that strain gauge readings from point $\mathrm{B}^{\prime}$ (mid-maxilla) were at times unattainable secondary to proximity of the lead wires from strain gauges $\mathrm{A}^{\prime}$ and $\mathrm{C}^{\prime}$. It was therefore decided to maintain only 3 standardized points at $\mathrm{A}^{\prime}, \mathrm{C}^{\prime}$, and $\mathrm{D}^{\prime}$ to ensure accurate recordings. Thus, 3 strain gauges were placed on each half of the maxilla for a total of 6 .

Standardized placement of strain gauges is accomplished according to bony landmarks on the skull (Fig $1)$. The first point established is point $S$. This is determined by dropping a vertical line parallel to the most 


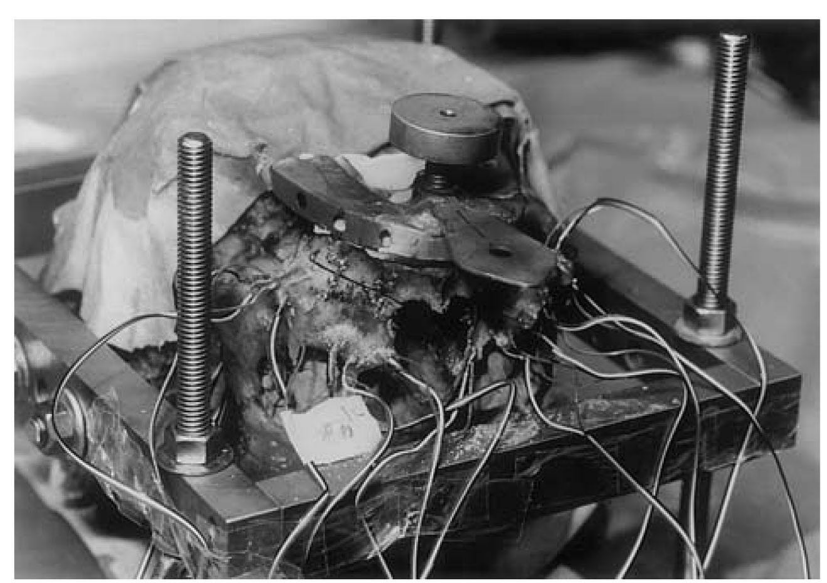

FIGURE 2. Photograph of cadaveric skull completely prepared to test after the osteotomy. The skull is held in the rectangular halo retainer, with the fixation tray and loading post attached. Strain gauges and the DVRT have been attached to the maxilla.

lateral aspect of the piriform rim and a horizontal line parallel to the inferior aspect at the piriform rim; the intersection of these 2 lines corresponds to point $S$. Point $\mathrm{E}$ is then determined $1 \mathrm{~cm}$ superior to the junction of the pterygomaxillary fissure. A line is drawn connecting point $\mathrm{E}$ to point $\mathrm{S}$. This line corresponds to our osteotomy line. Point A is established 5 $\mathrm{mm}$ distal to point $\mathrm{S}$. Point $\mathrm{C}$ is one half the distance between point $\mathrm{A}$ and point $\mathrm{E}$, along that line. Similarly, point $\mathrm{B}$ is established as one half the distance between point $\mathrm{A}$ and point $\mathrm{C}$. Last, point $\mathrm{D}$ is established as one half the distance between point $\mathrm{C}$ and point E. Strain gauges are placed $5 \mathrm{~mm}$ superior and parallel to the corresponding point $\mathrm{A}, \mathrm{B}, \mathrm{C}$, or $\mathrm{D}$. The placement of the strain gauge $\mathrm{A}^{\prime}$ corresponds to the piriform rim region, $\mathrm{B}^{\prime}$ to the mid-maxilla, $\mathrm{C}^{\prime}$ to the zygomatic buttress region, and $\mathrm{D}^{\prime}$ to the posterior zygomatic buttress region.

\section{TESTING RIG}

A 2-part testing rig (Fig 2) was designed to hold and position the skull for testing in a standard Instron Corporation (Canton, MA) testing machine. One part of the assembly is a frame attached to a rectangular "halo," and the other part is a custom tray with a perpendicular loading port extending from it. The compressive phase used a ball-bearing fixture to allow self-aligning and ensure transmission of a symmetrically centered vector force.

The rectangular halo is affixed to the skull via transcranial steel pins contained in a rigid stainless steel fixation frame. During compression testing, the fixation frame for the skull is bolted to an adaptor that threads into the testing machine. Placement of the transcranial steel bolts is standardized parallel to the maxillary arch for reference. During the test, the skull is held in the frame upside down with the mandible removed.
The point of load application on the skull is over the hard palate. This location is chosen to avoid problems that would occur with direct application of forces to the teeth. The teeth pose problems because they vary considerably in both the number of remaining teeth and mobility from individual to individual in the postmortem skull.

The loads to the hard palate are transmitted through a size-selected maxillary fixation tray (Fig 2) affixed to the hard palate with bone screws and acrylic resin. The tray covers the teeth, and acrylic is used as a filler material so that the load is transmitted to the maxillary arch and hard palate in a uniform manner. Care was taken to ensure the PMMA hardened with the top surface of the post of the fixation tray parallel to line SE on the skull with a bubble chamber used to level the fixation tray and the frame.

After the maxillary fixation tray is attached to the palate, it is connected to the Instron delivery post that is used to transmit the load. The post used for the compression test is a short solid rod with a center invagination allowing placement of a single ball bearing. This allows for automatic alignment of the post and centroidal transmission of compressive forces. During compression, the surface of the load carrying post is parallel to the custom tray and maxillary arch. Care is taken to ensure that the maxillary fixation tray is applied without any unwanted tilt and so that the vector of the applied force falls midway between the posterior and anterior plates. This is accomplished with the use of a bubble chamber level to apply the tray to the skull. If necessary, small adjustments can be made to the tilt of the load-carrying rod that connects to the fixation tray. This allows for reproducible alignment of the Instron machine to the skull.

Before testing in compression, the apparatus is positioned to ensure the hard palate is centered over the testing machine piston. The bolts that go through the halo are adjusted so that the hard palate is perpendicular to the direction of motion of the cross arm of the testing machine. An adaptor connects the bottom plate of the frame to the threads of the testing machine.

A universal testing apparatus is used to transmit the load to the skull. This machine has the capability of controlling the rate of application and accurately measuring the load applied and displacements of its crossarm. A DVRT is used to measure change in the gap distance.

\section{MOTION DETECTION}

The crucial parameter to evaluate absolute rigidity is the measurement of relative movement of the segments or collapse across the osteotomy. To detect this motion, a DVRT (differential variable reluctance transducer) and associated electronic equipment (Mi- 
croStrain, Inc, Burlington, VT), was used to measure an analog output in millivolts that is then calibrated to micrometers of displacement. This allowed for determination of gap distance change across the osteotomy site. Accuracy with the DVRT is within $\pm 0.5 \mu \mathrm{m}$ according to calibration curves from the manufacturer. Placement of the gap gauge was standardized to a specific locality bridging the osteotomy site $(1 \mathrm{~cm}$ distal to point $S$ on the left side of the skull).

\section{EXPERIMENTAL GROUPS AND SERIES}

The static loads were selected to span the likely range of maximum stresses experienced by the maxilla during masticatory function. ${ }^{10-13}$ Each skull was subjected to static compressive forces in incremental gradients of 5 kiloponds (kp), starting at $5 \mathrm{kp}$ up to a maximum of $60 \mathrm{kp}$. (One kilopond is equivalent to $9.81 \mathrm{~N}$ or the unit of force exerted by $1 \mathrm{~kg}$ at sea level.) These loads are placed at the predetermined amount and set rate of application. Recordings of 3 measurements were made per load per strain gauge per specimen. Between each load, a measurement was taken at zero load to re-zero the gauges. The amounts reported are the average of these 3 readings. Recordings of strain data are taken at initial application of the compressive force and then re-recorded 2 minutes later to allow viscoelastic effects to subside. The mean and standard deviation were determined for each strain gauge position (total of 6 strain gauges).

These force applications, although a first-order approximation, should not be considered an exact duplication of masticatory function. We used static loads that allowed time for a quasi-steady state measurement. Actual mastication is a dynamic process with complex constantly changing loading. Our method of applying the force also did not replicate the moment arm of the mandible with its complex muscular attachments. This study was an examination of strain patterns under a uniform loading situation that could serve as a basis for understanding more complex loading. The $5 \mathrm{kp}$ to $60 \mathrm{kp}$ force applications were chosen to cover the full range of average plus standard deviation of forces measured by other researchers on control, preoperative, postoperative, male, and female patients. ${ }^{11-13}$ Harada et al, ${ }^{13}$ using a pressuresensitive sheet, measured average and standard deviation bite forces of $6.2 \pm 4.2 \mathrm{kp}$ at 2 weeks postoperatively and $36.0 \pm 26.2 \mathrm{kp}$ at 6-month follow-up. Throckmorton and Ellis ${ }^{11}$ and Ellis et al ${ }^{12}$ measured the bite forces on individual teeth and found average values on the incisors as low as $5.6 \mathrm{kp}$ and as high as $40.4 \mathrm{kp}$ on molars with a standard deviation of $13.2 \mathrm{kp}^{12}$

\section{SURGICAL PLATING TECHNIQUE}

Once the initial intact skull data are collected, a standard Le Fort I osteotomy is created. The Le Fort I osteotomy is then rigidly fixated with the Walter Lorenz Surgical, Inc (Jacksonville, FL) Ultra-Micro osteosynthesis system. Surgical grade II, commercially pure titanium, 4-hole "L" plates (Walter Lorenz Surgical, Inc, No. 01-7078/01-7079) with self-tapping hex head 1.5- $\times$ 5-mm screws (Walter Lorenz Surgical, Inc, No. 01-7005) were used from that line. As is done in surgical practice, the plates are bent to conform to the contours of the individual cadaver skull. Holes were bored with a $1.0-\times 50-\mathrm{mm}, 5-\mathrm{mm}$ stop drill bit (Walter Lorenz Surgical, Inc, No. 01-7142). Additionally, the DVRT is placed at this time in the previously stated standard position. Four plates maintain a gap of approximately $2 \mathrm{~mm}$ across the osteotomy site with no bony contact.

Each maxillary osteotomy is rigidly fixated with 4 new plates and 16 screws. Changes across the osteotomy provide information regarding force capacity and resistance of the currently used plating system. The permanent gap changes secondary to the applied static load are recorded using the DVRT device.

\section{PLATE DEFORMATION ANALYSIS}

To investigate the permanent changes in the gap measurements, analytical calculations were performed to examine the predicted theoretical deformation resulting from axial loads, elastic and inelastic buckling, and lateral loading of the plates. Small deformation strength of material theory was used to analyze the plate undergoing axial deformation, elastic buckling, inelastic buckling, and bending of a beam fixed at one end. These analyses are not intended to fully describe the mechanics of our cadaver model with craniofacial plates but rather to explore the possible mechanisms that may be responsible for the permanent deformation that occurs in the plates.

\section{AXIAL DEFORMATION}

The plate was modeled as a column subjected to an axial load. Its deformation is described by the following equation

$$
\delta=\frac{P L}{A E}
$$

where $\delta$ is the amount of axial deformation, $P$ is the load applied, $L$ is the original length of the column, $A$ is the cross-sectional area of the column, and $E$ is the Young's modulus. The material is assumed to be isotropic and linearly elastic.

For the Lorenz plates used in this experiment, the cross-sectional area would be $0.6 \mathrm{~mm} \times 1.22 \mathrm{~mm}$ or $0.732 \times 10^{-6} \mathrm{~m}^{2}$. The length would be distance between the 2 center screws, $7 \mathrm{~mm}$ or $0.007 \mathrm{~m}$. The 
Young's modulus of commercially pure titanium is $110.3 \mathrm{GPa}\left(110.3 \times 10^{9} \mathrm{~N} / \mathrm{m}^{2}\right)$ in compression. ${ }^{14}$ For the load applied, we will assume that the highest load we applied in the experiment, $60 \mathrm{kp}$, is distributed evenly among the 4 plates. Thus each plate receives a load of $15 \mathrm{kp}$ or $147.15 \mathrm{~N}$. This gives us an axial deformation of $1.28 \times 10^{-5} \mathrm{~m}$ or $12.8 \mu \mathrm{m}$.

\section{ELASTIC BUCKLING}

The standard equation used to determine the load that is required to cause elastic buckling in a column was developed by Euler in 1744

$$
P_{c r}=\frac{\pi^{2} E I}{(k L)^{2}}
$$

where $P_{c r}$ is the critical load required to cause buckling. We modeled the plates as a column of $7 \mathrm{~mm}$, rigidly fastened at both ends. The constant $k$ is determined by how the ends of the column are constrained. It is 0.5 in a column with rigidly fixed ends and 1.0 in a column with pinned ends that are allowed to swivel about their fixation points. $E$ is the Young's modulus that we will take as the average of the Young's modulus of commercially pure titanium in compression (110.3 GPa) and in tension (106.9 $\mathrm{GPa}$ ) or $108.6 \mathrm{GPa} . I$ is the moment of inertia about the wide axis $(\mathrm{I}=1 / 12 \times 0.00122 \mathrm{~m} \times(0.0006$ $\left.\mathrm{m})^{3}=2.196 \times 10^{-14} \mathrm{~m}^{4}\right)$.

\section{INELASTIC BUCKLING}

The Johnson formula for the critical load for inelastic buckling can be used when the slenderness ratio

$$
\frac{k l}{r}
$$

(where $r$ is the radius of gyration of the cross section of the column defined as $\sqrt{I / A}$ ) is less than

$$
\sqrt{\frac{2 \pi^{2} E}{\sigma_{y}}}
$$

where $\sigma_{\mathrm{y}}$ is the yield stress $(88.3 \mathrm{MPa}$ for grade $2 \mathrm{cp}$ titanium). Our plates then meet the slenderness criteria of the Johnson's formula. The Johnson formula predicts the critical load to be

$$
P_{d r}=A\left[\sigma_{y}-\left(\frac{\sigma_{y} L}{2 \pi r}\right)^{2} \frac{1}{k E}\right]
$$

\section{BENDING OF A BEAM FIXED AT ONE END}

The plates are all loaded in the maxilla at an angle, and they are affixed to the maxilla with 4 screws. Their manner of fixations means that they can be subject to loads that are not aligned along the long axis of the plates and to bending moments. Also, the bone they are attached to has a much lower modulus of elasticity than the cp titanium used to make the plates. This means that the bone will have some freedom of motion to allow the plates to bend.

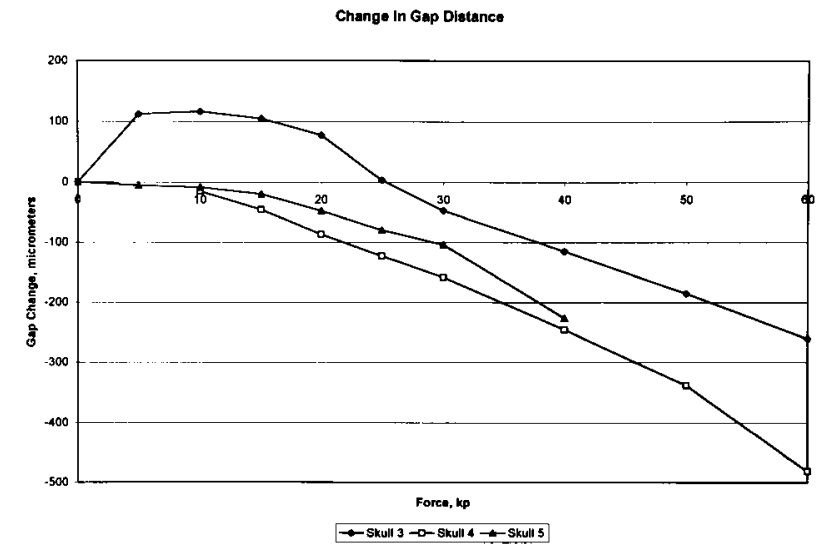

FIGURE 3. DVRT data from 3 osteotomized skulls showing the changes in the gap distance with increasing load for skull 3, skull 4 , and skull 5 .

For a $15-\mathrm{kp} \mathrm{load}$ at $10^{\circ}$, the component in the transverse direction is $2.60 \mathrm{kp}$ or $25.6 \mathrm{~N}$ in the transverse direction. The amount a cantilever beam would deflect from a load applied at the free end is given by the equation

$$
\delta_{\text {max }}=\frac{P L^{3}}{3 E I}
$$

where $\delta_{\max }$ is the deflection at the free end, $P$ is the transverse component of the load $(25.6 \mathrm{~N})$.

\section{Results}

\section{DVRT RESULTS}

The results of the DVRT data from the 3 osteotomized skulls show 2 regions of interest. A low-load response occurring in the 0 - to $15-\mathrm{kp}$ range and a high-load response occurring in the 15 - to 60 -kp range (Fig 3). In 2 of the skulls ( 4 and 5), the low-load response was a shallow downward curve. In skull 3, the gap increased transiently when small loads were applied. In the high-load region, there is a steeper and fairly progressive linear downward slope that is approximately the same order of magnitude for all 3 skulls. The retained a permanent deformation from 143 to $302 \mu \mathrm{m}$.

\section{PLATE DEFORMATION ANALYSIS}

For strictly axial forces, calculations show that under an axial compressive load of $60 \mathrm{kp}$ distributed equally among 4 plates (15 kp per plate), each of these plates would be expected to deform $12.8 \mu \mathrm{m}$. The Johnson buckling theory predicts that inelastic buckling will occur in these plates before elastic buckling due to their low slenderness ratios and that inelastic buckling can occur anywhere from 16.2 to $29.3 \mathrm{kp}$ depending on the boundary conditions assumed for the rigidity of the fixation of the column. For the bending analysis, with a 15-kp load applied at 


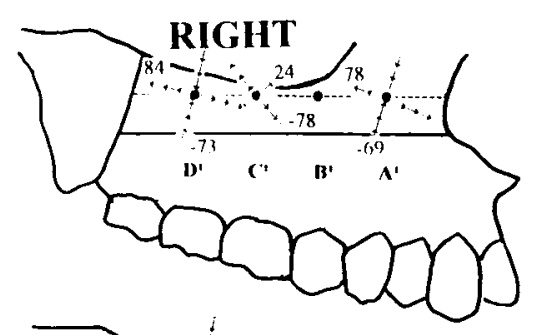

SKULL 5
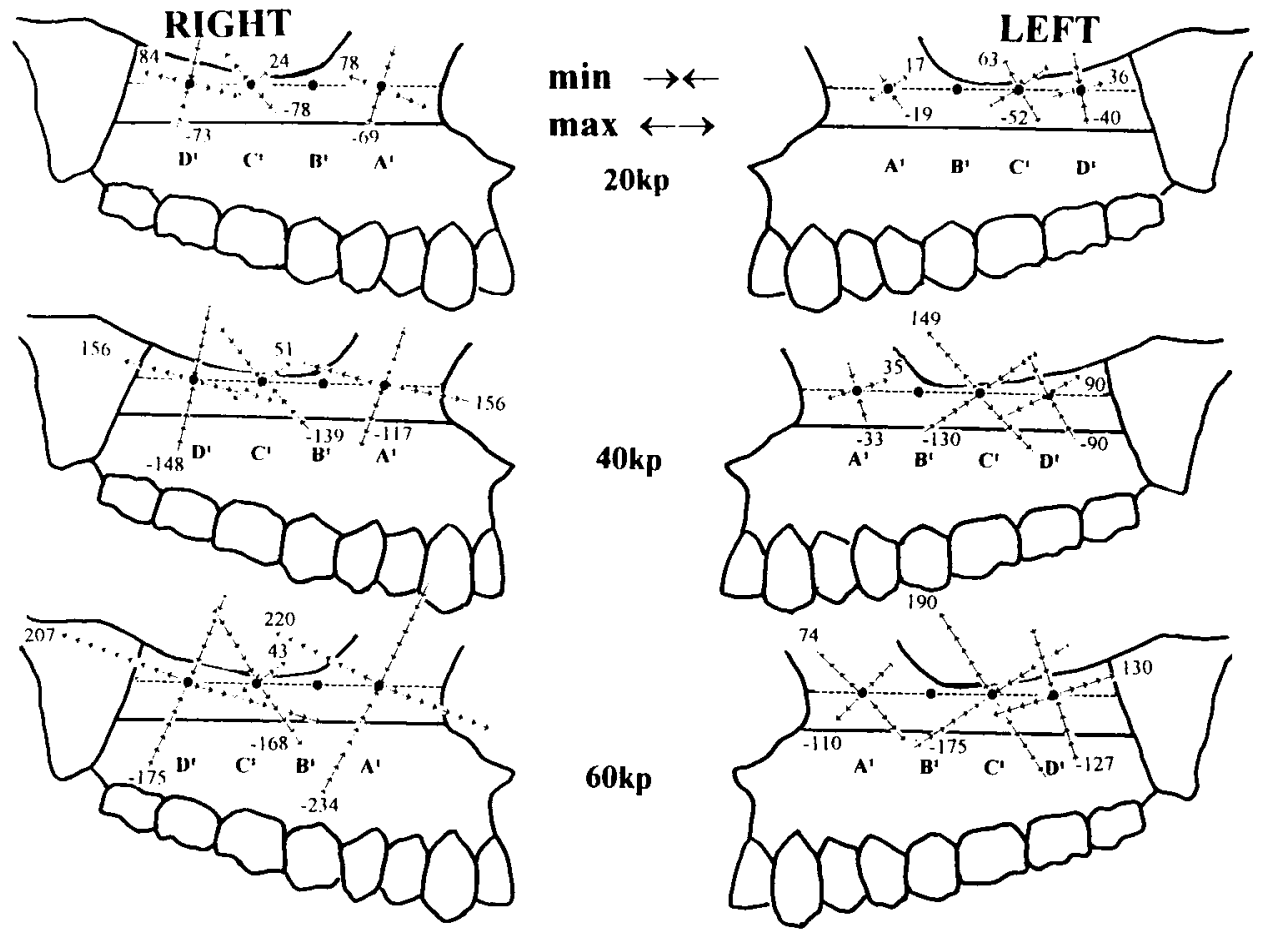

FIGURE 4. Graphic representation of strain vector magnitude and orientation of maximum and minimum principal strains at 20 , 40 , and $60 \mathrm{kp}$ (196, 392, and 589 N) for skull 5 for the intact configuration. the free end at an angle of $10^{\circ}$ from the long axis of the beam, theory predicts a maximum deflection of $1,225 \mu \mathrm{m}$.

\section{PRINCIPAL STRAINS}

For every load placed on each rosette gauge, maximum and minimum principal strains and their orientation were calculated. As a single case example, the vector magnitude and orientation of these strains at 20,40 , and $60 \mathrm{kp}$ for skull 5 are graphically illustrated in Figure 4 for the intact case. Positive values indicate tensile strain and negative values compressive strain. For each skull, it was noted that the orientation of the principal strains on the left side mirrored those on the right side. There was sometimes considerable difference in magnitude between the left and the right sides.

The average maximum and minimum principal strain values and standard deviations in units of microstrain are presented in Table 1 for the intact skulls and Table 2 for the osteotomy skulls. Strain is a dimensionless quantity defined as the change in length divided by the initial length. One microstrain is a deformation of 0.000001 of the original length or, to put it in units, $1-\mu \mathrm{m}$ deformation per meter original length. Positive values represent tensile strains and negative values indicate compressive strain. The load values shown are the average forces in kiloponds displayed by the force transducer during the reading of the strain gauges.
To better display how the maximum and minimum principal strains and their orientation changed with the load, the maximum principal strain versus load is plotted in Figure 5 for the intact and osteotomy cases, respectively, the minimum principal strain versus load in Figure 6 for the intact and osteotomy cases, respectively, and Figure 7 for the orientation of the maximum principal strains for the intact and osteotomy cases, respectively. The reader may have a better image of what these numbers physically mean at points $\mathrm{A}^{\prime}, \mathrm{B}^{\prime}, \mathrm{C}^{\prime}$ and $\mathrm{D}^{\prime}$ if we present a graphic representation of the principal strain vectors at 20 , 40 , and $60 \mathrm{kp}$ for the intact situation in Figure 8 and for the osteotomy case in Figure 9.

\section{Discussion}

\section{DVRT RESULTS}

The low-load response is probably due to a shifting and settling of position among the plates, the screws, and the bone. Permanent bending of the plates may account for the high-load response. This theory is supported in that a predominately axial load applied to the plates at the site of the screws can cause a significant amount of bending if the load is applied at a small angle to the long axis of the plate.

The transitory increase in the gap that occurred in skull three may have been due to a bridging effect from the plates combined with some load alignment 


\begin{tabular}{|c|c|c|c|c|c|c|c|c|c|}
\hline Average load & 4.7 & 9.4 & 13.8 & 18.6 & 23.5 & 28.4 & 37.7 & 47 & 56.5 \\
\hline SD & 0.3 & 0.4 & 0.2 & 0.3 & 0.2 & 0.8 & 0.6 & 0.3 & 1.9 \\
\hline \multicolumn{10}{|c|}{ Point A $(\mathrm{n}=5)$} \\
\hline $\operatorname{Max}$ & 47.4 & 54.7 & 84.1 & 105.1 & 137.2 & 178.8 & 244.9 & 306.3 & 374.4 \\
\hline SD & 27.3 & 51.4 & 82.2 & 91.5 & 131.2 & 168.8 & 240.2 & 289.7 & 371.5 \\
\hline Min & -32.0 & -47.0 & -53.8 & -70.8 & -82.3 & -121.8 & -186.6 & -241.0 & -313.8 \\
\hline SD & 34.0 & 38.0 & 46.1 & 54.8 & 67.4 & 111.8 & 168.2 & 195.1 & 244.4 \\
\hline Angle & -28.6 & -39.7 & 23.9 & 13.0 & 25.9 & 14.1 & 12.1 & 15.9 & 19.6 \\
\hline \multicolumn{10}{|c|}{ Point B $(\mathrm{n}=3)$} \\
\hline Max & -4.05 & -13.425 & -9.1 & -26.525 & -14 & -39.225 & -46.6 & -51.35 & -55.85 \\
\hline SD & 1.4 & 13.0 & 9.1 & 24.3 & 19.0 & 40.7 & 59.8 & 81.9 & 114.3 \\
\hline Min & -22.1 & -57.2 & -66.9 & -99.1 & -98.0 & -143.8 & -185.0 & -218.0 & -262.8 \\
\hline SD & 16.5 & 13.0 & 14.9 & 28.7 & 34.0 & 56.9 & 85.1 & 107.5 & 152.9 \\
\hline Angle & -68.6 & -60.7 & -55.5 & -53.3 & -45.9 & -47.9 & -42.1 & -37.7 & -35.0 \\
\hline \multicolumn{10}{|c|}{ Point C $(n=8)$} \\
\hline $\operatorname{Max}$ & 15.0 & 23.4 & 35.7 & 38.8 & 59.1 & 57.4 & 89.0 & 108.8 & 126.0 \\
\hline SD & 15.5 & 23.3 & 44.5 & 49.2 & 69.7 & 68.7 & 84.6 & 105.6 & 124.8 \\
\hline Min & -44.2 & -52.9 & -85.3 & -93.6 & -139.0 & -143.7 & -192.1 & -234.0 & -286.7 \\
\hline SD & 17.3 & 40.0 & 60.1 & 75.2 & 98.2 & 135.1 & 183.2 & 221.8 & 278.8 \\
\hline Angle & -57.3 & -57.1 & -43.5 & -50.1 & -46.9 & -45.8 & -48.0 & -48.6 & -48.5 \\
\hline \multicolumn{10}{|c|}{ Point D $(\mathrm{n}=4)$} \\
\hline Max & 37.9 & 73.9 & 119.0 & 150.0 & 189.6 & 205.5 & 254.5 & 314.8 & 368.8 \\
\hline SD & 26.1 & 41.5 & 73.4 & 92.4 & 113.3 & 96.4 & 134.3 & 172.8 & 207.0 \\
\hline Min & -34.6 & -49.1 & -73.3 & -98.8 & -120.4 & -123.2 & -154.4 & -197.5 & -223.8 \\
\hline SD & 25.1 & 55.8 & 87.3 & 118.8 & 151.6 & 170.9 & 198.6 & 257.1 & 309.1 \\
\hline Angle & 29.325 & 36.325 & 36.975 & 36.15 & 36.2375 & 33.675 & 35.175 & 35.2 & 33.75 \\
\hline
\end{tabular}

NOTE. Strains are expressed in microstrain and average load in kiloponds. The angle orientation is the angle the maximum principal strain deviates from the vertical.

errors that occurred in that early sample. The phenomenon has not reoccurred in any subsequent skull, including a later fresh cadaver skull not reported here.

\section{PLATE DEFORMATION ANALYSIS}

In all 3 skulls, a permanent change in the gap distance was noted. This change occurred after placement of a 10-kp load in all the skulls tested. The possible causes that account for the permanent gap changes include 1) bending of the plate, 2) elastic or inelastic buckling of the plate, 3) axial deformation of the plates, 4) movement at the bone-screw interface, and 5) movement at the plate-screw interface. Initial shifting of the bone plate, screw, and osseous interface likely accounts for the low-load change below 10 $\mathrm{kp}$. Our theoretical analysis rules out elastic buckling and axial deformation as a principal cause of the permanent change in the gap. For strictly axial forces, calculations show that axial elastic deformation would account for $12.8 \mu \mathrm{m}$ of deformation total for the 4 plates and only $9 \%$ of the lowest permanent gap deformation value. The possibility of elastic buckling was ruled out because standard elastic deformation theory required a load of 20.5 to $33.5 \mathrm{kp}$ per plate, much more than was achieved in this study. Lateral bending of the plate due to likely off-axis loading can account for the entire permanent gap.
Although we believe that inelastic buckling is remotely possible, we believe that it is unlikely because 1) in general the range of predicted critical loads is greater than what we believe a single plate experiences and 2) a sudden buckling type of failure has been observed in only 1 plate in 1 skull. The ASTM standards for grade II cp titanium require that it have a yield strength between 275 and $450 \mathrm{MPa} .{ }^{14}$ Depending on the boundary conditions assumed for the rigidity of the fixation of the column, the effective column length, and the precise yield point of the titanium, the Johnson formula predicts that an inelastic type of buckling can occur anywhere from 16.2 to $29.3 \mathrm{kp}$. Thus, if the plates are unevenly loaded and if the material in a particular plate has a particularly low yield strength, inelastic buckling may have occurred. However, the only skull that experienced a catastrophic failure of the plates was skull 5, where a plate bent or buckled suddenly at a load of $47 \mathrm{kp}$ (an average of only $11.8 \mathrm{kp}$ per plate).

\section{PRINCIPAL STRAINS}

The skulls plated after the Le Fort I osteotomy displayed a strain pattern greatly perturbed from the intact pattern. In general, the average maximum and minimum principal strains were less linear over the range of loads applied and the standard deviations 


\begin{tabular}{|c|c|c|c|c|c|c|c|c|c|}
\hline Average load & 4.6 & 9.1 & 13.8 & 18.4 & 23.0 & 28.4 & 37.5 & 47.4 & 56.5 \\
\hline SD & 0.4 & 0.5 & 0.6 & 1.0 & 1.5 & 1.3 & 1.7 & 2.0 & 2.1 \\
\hline \multicolumn{10}{|c|}{ Point A $(\mathrm{n}=3)$} \\
\hline $\operatorname{Max}$ & 68.6 & 125.4 & 161.2 & 149.2 & 127.3 & 172.1 & 174.2 & 217.7 & 229.6 \\
\hline SD & 61.8 & 45.6 & 64.1 & 61.2 & 102.3 & 130.8 & 163.0 & 189.2 & 204.5 \\
\hline Min & -77.9 & -97.6 & -148.2 & -151.4 & -156.5 & -223.4 & -253.6 & -309.2 & -352.6 \\
\hline SD & 34.6 & 22.2 & 51.6 & 65.5 & 49.4 & 73.8 & 105.3 & 133.0 & 163.4 \\
\hline Angle & 19.3 & 29.1 & 30.8 & 29.9 & 32.4 & 30.6 & 29.6 & 30.2 & 26.6 \\
\hline \multicolumn{10}{|c|}{ Point B $(\mathrm{n}=3)$} \\
\hline Max & 98.2 & 160.2 & 226.5 & 311.2 & 433.1 & 515.5 & 534.3 & 520.5 & 431.6 \\
\hline SD & 45.1 & 80.9 & 136.9 & 210.1 & 321.6 & 409.0 & 452.7 & 468.0 & 436.6 \\
\hline Min & -68.7 & -100.5 & -114.8 & -136.0 & -183.4 & -260.3 & -259.8 & -267.4 & -255.1 \\
\hline SD & 214.9 & 307.5 & 375.5 & 445.9 & 489.2 & 526.2 & 572.6 & 639.7 & 665.0 \\
\hline Angle & -19.2 & -20.4 & -19.5 & -16.4 & -14.4 & -13.4 & -13.5 & -13.9 & -10.2 \\
\hline \multicolumn{10}{|c|}{ Point C $(n=6)$} \\
\hline $\operatorname{Max}$ & 51.7 & 143.4 & 179.4 & 191.7 & 208.5 & 246.8 & 267.6 & 301.5 & 350.4 \\
\hline SD & 27.0 & 89.5 & 114.0 & 107.8 & 110.1 & 134.4 & 143.1 & 176.8 & 236.3 \\
\hline Min & -76.3 & -108.6 & -136.5 & -168.7 & -192.0 & -222.5 & -265.7 & -309.7 & -345.9 \\
\hline SD & 131.8 & 172.9 & 215.4 & 275.2 & 320.4 & 381.8 & 470.2 & 580.8 & 670.4 \\
\hline Angle & -25.3 & -10.5 & -9.9 & -10.6 & -10.8 & -10.5 & -17.0 & -12.1 & -12.7 \\
\hline \multicolumn{10}{|c|}{ Point D $(\mathrm{n}=2)$} \\
\hline Max & -0.4 & 70.8 & 93.7 & 193.0 & 81.5 & 50.6 & 40.4 & & \\
\hline SD & 19.9 & 20.2 & 54.8 & 181.4 & 30.7 & 20.1 & 24.0 & & \\
\hline Min & -38.0 & -2.2 & -18.0 & -40.1 & -17.7 & -7.2 & -2.3 & & \\
\hline SD & 30.8 & 13.2 & 2.5 & 51.8 & 8.8 & 8.3 & 4.7 & & \\
\hline Angle & 8.9 & -25.3 & -18.5 & -25.0 & -24.6 & -20.6 & -21.1 & & \\
\hline
\end{tabular}

NOTE. Strains are expressed in microstrain and average load in kiloponds. The angle orientation is the angle the maximum principal strain deviates from the vertical.

were much greater. In the osteotomy skulls the maximum principal strains at points $\mathrm{A}$ and $\mathrm{D}$ were decreased compared with the intact skull, whereas the maximum principal strains at points $\mathrm{B}$ and $\mathrm{C}$ were increased.

Large standard deviations, as found in the strain measurements in this study, must be expected in samples taken from human donors. Standard deviations as large as $60 \%$ of the mean are frequently encountered in data gathered from human subjects,

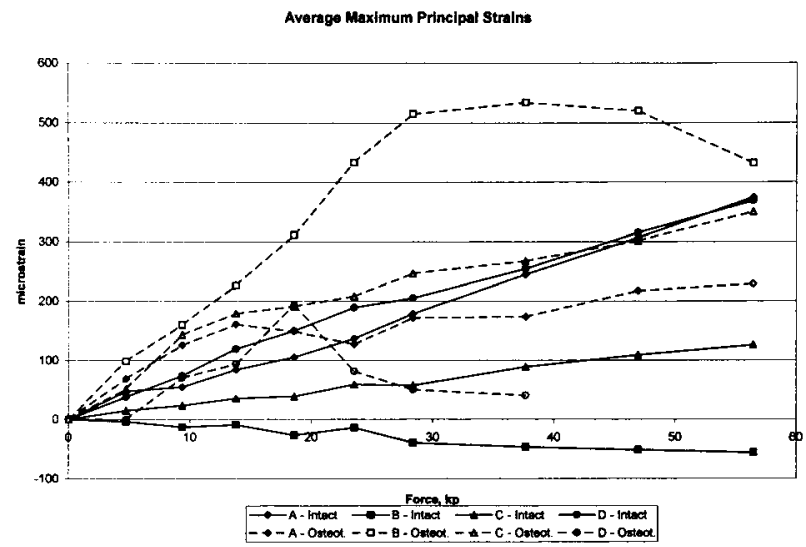

FIGURE 5. Average maximum principal strains for 3 embalmed skulls at points $A, B, C$, and $D$ versus load for the intact case (solid lines) and the osteotomy case (broken lines). such as the previously mentioned bite force data. ${ }^{11-13}$ While we were provided information about the age, gender, and cause of death of the donors, we were unable to obtain information about chronic conditions or the general mass and bone density of the entire skeleton. Coming "as is" from the general donor population, these heads were not and could not be standardized to a specific size, bone density, bone thickness, anatomy, or elastic or viscoelastic proper-

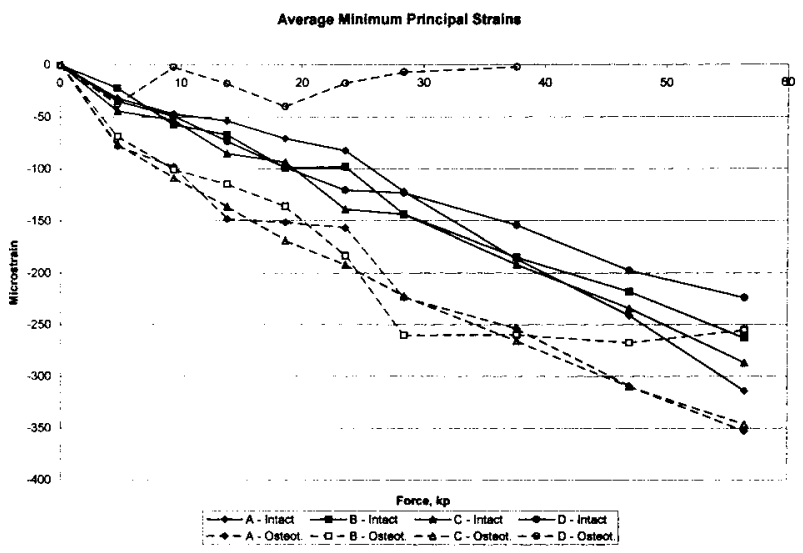

FIGURE 6. Average minimum principal strains for three embalmed skulls at points A, B, C, and D versus load for the intact case /solid lines) and the osteotomy case (broken lines). 


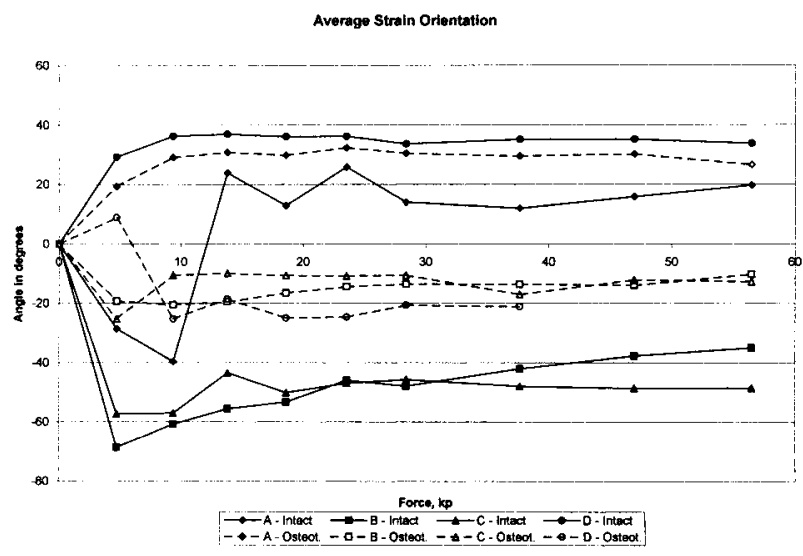

FIGURE 7. Average orientation of the maximum principal strains for 3 embalmed skulls at points A, B, C, and D versus load for the intact case (solid lines) and the osteotomy case (broken lines).

ties. All of these variables contribute to the variance found in this study.

A significant reduction of variance can be achieved by using a synthetic model of the skull. However, such a model would be severely challenged to adequately model the geometry, modulus, and viscoelasticity of the human skull. A standardized synthetic model would have to be validated by a biologic model such as this one.

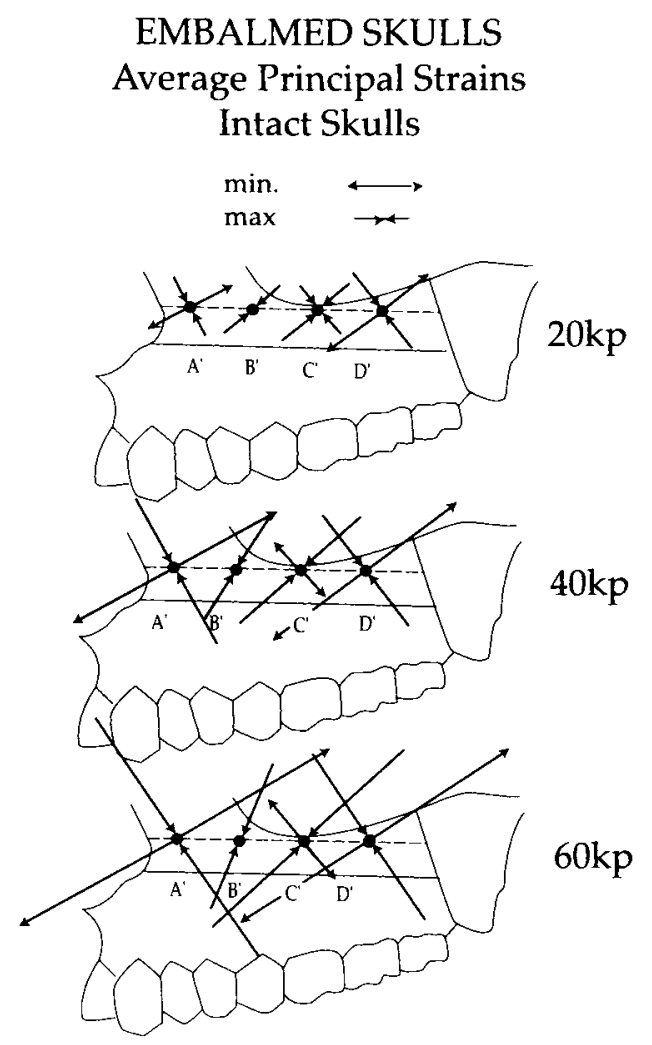

FIGURE 8. Graphic representation of average strain vector magnitude and orientation of maximum and minimum principal strains at 20 40 , and $60 \mathrm{kp}$ for 3 skulls for the intact configuration.

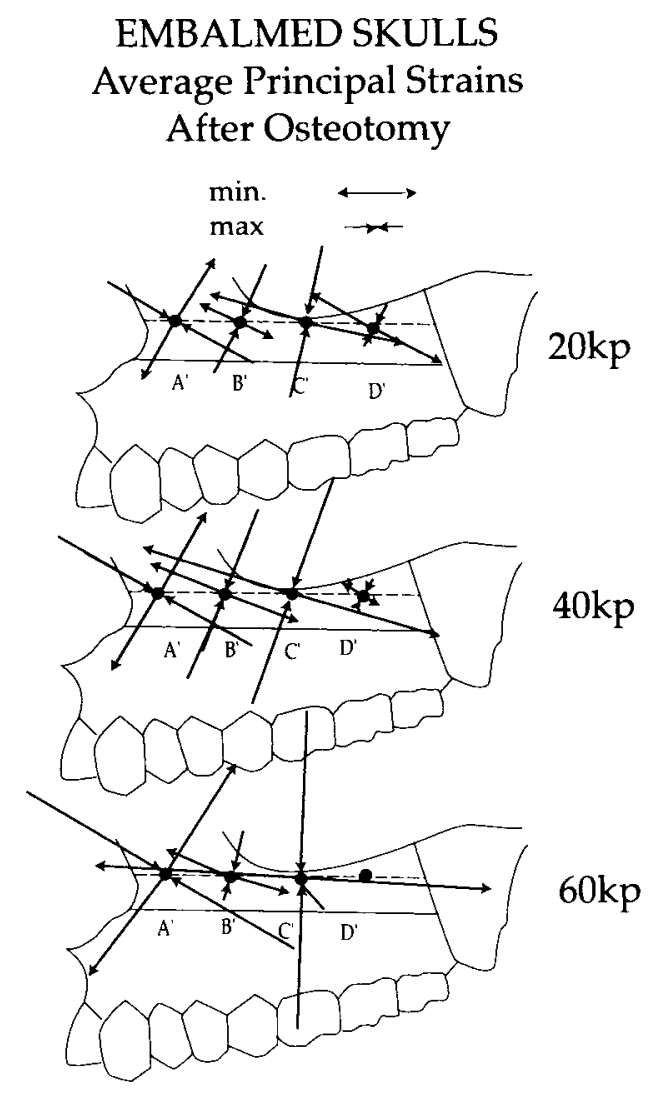

FIGURE 9. Graphic representation of average strain vector magnitude and orientation of maximum and minimum principal strains at 20 , 40 , and $60 \mathrm{kp}$ for 3 skulls for the osteotomy configuration.

One of the limitations of this initial model is the static rather than dynamic nature of the load. Rate of application would likely have a significant effect on changes, as well as strain patterns. Other components of force, such as shear, that would occur with normal excursive movements are not fully accounted by this model. To alleviate some of these problems, a more sophisticated material testing machine with hydraulic controls and real-time computer-recorded strain data could be used for greater flexibility and control. Collection of "real-time" data would allow for the examination of the viscoelastic (time dependent elasticity) of the skull.

This model proves to be reliable in measuring strain patterns in the human maxilla at predetermined sites. This is supported by the linear relationship that exists in both maximum and minimum principal strain patterns relative to increasing incremental compressive load. These strain patterns appear to be consistent with graduated loading forces. It should be noted that although axial compressive loads were placed, substantial tensile forces existed. These tensile forces caused an anterior and superior displacement of the maxilla. The principal strain graphs also show that the region of greatest resistance to compression lies just 
posterior to the zygoma and that point B (mid-maxilla) is stress shielded by the piriform rim and zygomatic buttress.

\section{References}

1. Leonard MS: Rigid internal fixation, facts versus fallacies. Oral Maxillofac Clin North Am 2:29, 1990

2. Jones JK, Van Sickels J. Rigid fixation: A review of concepts and treatment of fractures. Oral Surg 65:13, 1988

3. Champy M, Lodde JP, Schmidtt R, et al: Mandibular osteosythesis by miniature screwed plates via a buccal approach. $\mathrm{J}$ Oral Maxillofac Surg 36:14, 1978

4. Ahl T, Dalen N, Lundberg A, et al: Biodegradable fixation of ankle fractures. Acta Orthop Scand 65:166, 1994

5. Surronen R, Pohjonen T, Vasenius J, et al: Comparison of absorbable self-reinforced multilayer poly-l-lactide and metallic plates for the fixation of mandibular body osteotomies: Experimental study in sheep. J Oral Maxillofac Surg 50:255, 1992

6. Cutright DE, Perez B, Beasley JD 3d, et al: Degradation rates of polymers and copolymers of polylactide and polyglycolic acids. Oral Surg Oral Med Oral Pathol 32:142, 1974

7. Bergsma EJ, Rozema FR, Bos RRM, et al: Foreign body reactions to resorbable poly (l-lactide) bone plates and screws used for the fixation of unstable zygomatic fractures. J Oral Maxillofac Surg 51:666, 1993

8. Ko R: The tension test upon the compact substance of the long bones of human extremities. J Kyoto Pref Med Univ 53:503, 1953

9. Roberts VL: Strain gauge techniques in biomechanics. Soc Exp Mech SESA 6:1, 1966

10. Tate GS, Throckmorton GS, Ellis E III, et al: Estimated forces in patients before orthognatic surgery. J Oral Maxillofac Surg 52:130, 1994

11. Throckmorton GS, Ellis E: the relationship between surgical changes in dental facial morphology and changes in maximum bite force. J Oral Maxillofac Surg 59:620, 2001

12. Ellis E III, Throckmorton GS, Sin DP: Bite forces before and after surgical correction of mandibular prognathism. J Oral Maxillofac Surg 54:176, 1996

13. Harada K, Watanabe M, Ohkura K, et al: Measure of bite forces and occlusal contact area before and after bilateral sagittal split ramus osteotomy of the mandible using a new pressure-sensitive device: A preliminary report. J Oral Maxillofac Surg 58:370, 2000

14. American Society of Testing of Materials: F67 Specification for unalloyed titanium for surgical implant application. in 1999 Annual Book of ASTM, Vol. 13.01, Philadelphia, PA, ASTM, 1994, pp 1-3 